\title{
UMA PERSPECTIVA EDUCOMUNICATIVA ACERCA DA PUBLICIDADE DA MARCA NATURA $^{1}$
}

Larissa Crepaldi Trindade, Mariangela Fazano Amendola

Universidade do Oeste Paulista - UNOESTE. Curso de Comunicação Social, Presidente Prudente, SP. e-mail: larissa@unoeste.br

\section{RESUMO}

O presente artigo, pretende analisar o vídeo publicitário da campanha institucional "Toda relação é um presente" da marca Natura, focalizando em perspectivas analíticas e reflexivas nos âmbitos educacional, arquetípico e semiótico. Esta abordagem multidisciplinar revela-se como uma importante ferramenta de análise do referido texto midiático, no sentido de extrair mensagens implícitas e explícitas que colaboram para o desenvolvimento social, cultural e humano, na esfera da educação.

Palavras-chave: educação; arquétipos; semiótica; Natura.

\section{AN EDUCOMMUNICATIVE PERSPECTIVE ON THE NATURA BRAND ADVERSITING}

\begin{abstract}
This article analyzes the institutional video advertising campaign "Every relationship is a gift" Natura brand, focusing on analytical and reflective perspectives in educational contexts, archetypal and semiotic. This multidisciplinary approach reveals itself as an important tool of analysis of the media text in order to extract implicit and explicit messages that contribute to the social, cultural and human development in education.
\end{abstract}

Keywords: education; archetypes; semiotics; Natura.

\footnotetext{
${ }^{1}$ Trabalho confeccionado para estudo pormenorizado atrelado ao Grupo de Estudos em Educação, do Mestrado em Educação da UNOESTE, aceito para publicação no DT 6 - Interfaces Comunicacionais do XIX Congresso de Ciências da Comunicação na Região Sudeste, realizado de 22 a 24 de maio de 2014.
} 
UMA PERSPECTIVA EDUCOMUNICATIVA

ACERCA DA PUBLICIDADE DA MARCA

NATURA

Muito se sabe que a Publicidade, desde que viveu sua revolução criativa na década de 60 e atualmente adentrando ao século XXI, constitui-se em objeto de análise no que diz respeito a sua função pedagógica e educativa perante a sociedade. Por ser construída com linguagem própria, fazendo uso de diversas estratégias textuais e visuais, a Publicidade tornou-se motivo de estudo de educadores com vistas a perceber a influência de seu discurso em públicos específicos, definidos anteriormente pela marca.

Durante esse processo analítico, educadores e especialistas em linguagem, procuram encontrar no interior do discurso publicitário, elementos que configurem violação ou impacto aos aspectos educativos comportamentais, aos valores sociais e às estratégias de incitação ao consumo.

Justamente por essa necessidade de verificar conteúdos veiculados nos meios de comunicação, é que se deu início ao conceito de gestão do dialogismo educativo, em um contexto marcado pelas múltiplas mediações sociais sobre cujos impactos não se tem domínio.

Ao notar que a presença das mídias proporcionam mediações culturais educativas junto à sociedade é que o sistema educativo entende a necessidade de uma área que avalie a interface entre Educação e Comunicação com vistas a entender e orientar o processo de recepção de conteúdos midiáticos.

O presente estudo pretende realizar uma breve análise do conteúdo da campanha "Toda relação é um presente", de cunho institucional da marca Natura. A análise buscará identificar a presença de arquétipos predominantes e subjacentes à marca e, então observar o possível impacto dessa comunicação em relação à educação, aos comportamentos, valores sociais e na condução do imaginário. Para tanto, será utilizado o método estruturalista da Semiótica francesa de Algirdas Julien Greimas, especificamente os conceitos de Temas e Figuras, para constatar a ancoragem ideológica efetivada pela enunciação da mensagem escolhida, na tentativa de provar, por meio do raciocínio hipotético-estrutural que o discurso tem conteúdo latente e educativo.

A pesquisa na área da Comunicação/Educação justifica-se por ser considerado um território que auxilia na construção de sentidos sociais, dos quais o cotidiano se impregna.

As comunicações mediatizadas ampliam desmesuradamente as informações disponíveis, oferecem imagens (do mundo ou virtuais) de modo proliferante, criam contatos entre áreas 
(geográficas, contextuais, temáticas, processuais) antes praticamente separadas, aceleram interações. Os usuários, ao selecionar em meio à profusão da oferta, movidos por critérios pessoais, mas sobretudo culturais-sociais, devem resolver problemas práticos para realizar essa tomada de decisão. Selecionados seus produtos mediáticos, os usuários não simplesmente os "absorvem", mas interagem com estes, sofrem suas interpelações, reagem, interpretam. E aí já temos aprendizagem. (BRAGA; CALAZANS, 2001, p. 92).

Ao reconhecer os meios de comunicação como um lugar de saber, passível de atuar juntamente com a escola e demais agentes de socialização, faz-se necessário fundamentar práticas que permitam a recepção e interpretação ativa mediada por estratégias de formação de sujeitos conscientes, críticos diante dos conteúdos diversos recebidos.

A metodologia do estudo centrou-se na análise de conteúdo com a utilização do sistema de arquétipos, com o método da inferência, que pretende extrair conhecimentos latentes do objeto analisado e a técnica da análise estrutural, focando na observação e reflexão de mecanismos discursos propostos por Algirdas Julien Greimas como os dispositivos de Isotopia temática e figurativa, que auxiliarão ainda mais na tentativa de comprovar como o uso de determinados elementos simbólicos pertencentes ao inconsciente coletivo, fornecem uma estrutura coerente e pertinente ao posicionamento da marca e ao mesmo tempo, no caso de Natura, influenciam de forma positiva e educativa a sociedade.

A análise estrutural possibilita que a investigação destes fenômenos seja viável, tendo em vista que a cultura e a sociedade foram historicamente construídas pela ação do homem e que existem estruturas ocultas que podem explicar seus hábitos.

O sistema de arquétipos é um método de criação de significados para as marcas diante da sociedade, encontrado em estudo realizado e publicado por Margaret Mark e Carol S. Pearson em sua obra "O herói e o fora da lei - como construir marcas extraordinárias usando o poder dos arquétipos".

Para Jung, Campbell e outros, nascemos com uma ressonância instintiva a essas históricas arquetípicas, por causa das muitas configurações da nossa mente. Portanto, o significado de um produto pode ser rapidamente comunicado pela simples evocação de uma história ou de um conceito que produz, em quem o vê, o reconhecimento instintivo de alguma verdade fundamental e identificável. Os arquétipos são o "software" da psique. Um ou outro programa arquetípico está ativado e 
envolvido o tempo todo. (MARK; PEARSON, 2012)

Na análise de conteúdo, "a inferência é considerada uma operação lógica destinada a extrair conhecimentos sobre os aspectos latentes da mensagem analisada." (BARDIN, 1988, p. 39-40, apud, DUARTE; BARROS, 2006, p. 284).

A evolução do estudo apresenta-se pelo conhecimento histórico e filosófico da marca Natura, pela apresentação de conceitos dos doze arquétipos, e posteriormente, pela análise do objeto de estudo e seu impacto educativo.

\section{A MARCA NATURA}

A Natura é uma marca $100 \%$ brasileira, presente em sete países da América Latina e na França. É a indústria líder no mercado brasileiro de cosméticos, fragrâncias, higiene pessoal e venda direta Trata-se de uma marca de expressão mundial, identificada com a comunidade das pessoas que se comprometem com a construção de um mundo melhor através da melhor relação consigo mesmas, com o outro, com a natureza da qual fazem parte e com o todo. Sua Razão de Ser é criar e comercializar produtos e serviços que promovam o bem-estar/estar bem, atualmente slogan da marca em suas campanhas e produtos. (NATURA, 2014)
Bem-estar: é a relação harmoniosa, agradável, do indivíduo consigo mesmo, com seu corpo.

Estar bem: é a relação empática, bemsucedida, prazerosa, do indivíduo com o outro, com a natureza da qual faz parte, com o todo.

A Natura acredita que o compromisso com a verdade é o caminho para a qualidade das relações. Quanto maior a diversidade das partes, maior a riqueza e a vitalidade do todo. A busca da beleza, legítimo anseio de todo ser humano, deve estar liberta de preconceitos e manipulações. (NATURA, 2014)

A empresa, organismo vivo, é um dinâmico conjunto de relações. Seu valor e sua longevidade estão ligados à sua capacidade de contribuir para a evolução da sociedade e seu desenvolvimento sustentável. Tem como premissa que uma empresa ambientalmente responsável deve identificar os impactos sobre o meio ambiente, buscando minimizar aqueles que são negativos e amplificar os positivos. (NATURA, 2014)

Suas diretrizes para o meio ambiente contemplam a responsabilidade para com as gerações futuras; a educação ambiental; o gerenciamento do pacto no meio ambiente e do ciclo de vida de produtos e serviços; a minimização de entradas e saídas de materiais. (NATURA, 2014) 
Sem alterar o padrão tecnológico atual da empresa, procuram reduzir o consumo de energia, água, produtos tóxicos e matérias-primas, e implantar processos de destinação adequada de resíduos. Investem na atualização de seu padrão tecnológico, visando a redução ou substituição de recursos de entrada. Realizam o tratamento de efluentes e de resíduos em geral e promovem o uso de matérias-primas renováveis (NATURA, 2014).

Possuem processos para medir, monitorar e auditar os aspectos ambientais associados ao consumo de recursos naturais e à geração de resíduos, estabelecendo periodicamente novas metas. Procuram adotar práticas de bom manejo florestal na extração de ativos e na utilização sustentável de recursos naturais básicos. Promovem a reciclagem e o reuso de materiais, 0 gerenciamento da qualidade do ar (com foco na redução das emissões de gases de efeito estufa), água e do solo, o controle de efeitos sonoros, a redução do desperdício e privilegiam o uso de materiais reciclados, entre outras iniciativas. (NATURA, 2014).

Todos os produtos vêm com uma tabela ambiental, semelhante às tabelas nutricionais existentes nos alimentos, apresentando informações que dão transparência sobre a origem e impacto de suas fórmulas e embalagens, incentivando assim o consumo consciente. (NATURA,
Desde dezembro de 2006 não realizam testes em animais para avaliação de segurança e eficácia durante o desenvolvimento de seus produtos ou de matérias-primas exclusivas. Essa decisão está totalmente alinhada com a razão de ser da marca, que se traduz no desenvolvimento e comercialização de produtos e serviços que promovam o bem estar bem. (NATURA, 2014)

A empresa estabeleceu com seus consumidores um relacionamento baseado no respeito e no compromisso com a verdade, seja por meio de suas consultoras e consultores, dos seus produtos ou dos veículos de comunicação. Procuram abraçar a diversidade sóciocultural em sua propaganda e se posicionam claramente contra a manipulação e o estereótipo.

\section{ARQUÉTIPOS}

Os autores Mark e Pearson (2012), afirmam que os arquétipos são formas ou imagens de natureza coletiva, que ocorrem em praticamente toda a Terra como componentes de mitos e, ao mesmo tempo, como produtos individuais de origem inconsciente.

A publicidade sempre se utilizou desse artifício de usar imagens arquetípicas para vender produtos, pois eles fazem parte do repertório coletivo, o que vai muito além de apenas usar essas imagens e símbolos arquetípicos - para posicionar a marca, pois 
ao longo do tempo, a própria marca assume significação simbólica. (MARK; PEARSON, 2012)

O significado de uma marca
é seu ativo mais precioso e
insubstituível. Quer você
esteja vendendo um
refrigerante ou um
candidato a presidente,
aquilo que sua marca
significa para as pessoas
será tão absolutamente
importante quanto sua
função - talvez até mais -
porque é seu significado
que nos diz que "este me
parece perfeito" ou "é este
que eu quero". 0
significado falar ao
sentimento, ou lado
intuitivo, do público; cria
uma afinidade emocional,
permitindo quer os
argumentos mais racionais
sejam ouvidos. (MARK;
PEARSON, 2012, p. 24,
grifos do autor).

Diante da teoria dos arquétipos podese discutir as relações que se estabelecem no imaginário de uma determinada cultura, de um dado grupo, ou seja, é uma construção coletiva que se baseia na memória social daquele grupo.

Essa memória coletiva é que vai respaldar o modo que os indivíduos/sujeitos se veem no confronto com o outro, a ação deles em relação aos demais e em relação às instituições. Há sempre uma relação de materialidade social com sua

interpretação, conformando um âmbito de ficção/realidade, construção/reconstrução, reflexo/refração.

(BACCEGA, 2005, p. 12).

Portanto, a estratégia de utilização de arquétipos para promover significado para as marcas faz com que no momento de recepção e interação de produtos midiáticos do enunciador com o enunciatário possa existir processos de identificação, projeção ou repulsa da marca diante dos valores apresentados em sua comunicação, que podem vir ou não ao encontro de sua memória social.

Pode-se notar que a teoria arquetípica ao desconstruir diálogos das marcas nos é permitido perceber quais são os sentidos sociais construídos, quais as sensibilidade a serem despertadas e principalmente a sua influência na formação de valores.

Na Grécia e Roma Antigas, os arquétipos formavam a base de mitos, mostrados com deuses e deusas, associandose aos 12 arquétipos citados anteriormente. (MARK; PEARSON, 2012)

Após a base arquetípica das marcas de sucesso serem estudadas, foram descobertos 12 arquétipos principais que se expressavam frequentemente na atividade comercial Da atualidade, sendo eles: 
Quadro 01. Estudo sobre arquétipos

\begin{tabular}{|c|c|}
\hline \multicolumn{2}{|c|}{ OS ARQUÉTIPOS E SUAS CARACTERÍSTICAS } \\
\hline Arquétipo & Características \\
\hline Criador & $\begin{array}{l}\text { É aquele que inova, cria e inventa. É } \\
\text { autêntico e acredita no poder da } \\
\text { imaginação. }\end{array}$ \\
\hline Prestativo & $\begin{array}{l}\text { É generoso e zeloso. É movido pela } \\
\text { compaixão e pelo desejo de ajudar os } \\
\text { outros. }\end{array}$ \\
\hline Governante & $\begin{array}{l}\text { É aquele que quer conquistar e manter o } \\
\text { poder. Quer estar no controle. Dominador } \\
\text { e autoritário. }\end{array}$ \\
\hline Bobo da Corte & $\begin{array}{l}\text { É aquele que gosta de travessuras, de } \\
\text { brincar e de se divertir e divertir os outros. }\end{array}$ \\
\hline Cara Comum & $\begin{array}{l}\text { É aquela pessoa comum, igual as outras e } \\
\text { seu desejo é se conectar com o mundo. }\end{array}$ \\
\hline Amante & $\begin{array}{l}\text { É aquele que ama e seduz. É romântico, } \\
\text { atraente e erótico. Seu desejo é conseguir } \\
\text { intimidade e expressar o prazer sensual. }\end{array}$ \\
\hline Herói & $\begin{array}{l}\text { É aquele que triunfa sobre o mal, a } \\
\text { adversidade ou grande desafio. Ele é } \\
\text { corajoso, competente e destemido. }\end{array}$ \\
\hline Fora-da-lei & $\begin{array}{l}\text { É aquele que quebra as regras, o } \\
\text { revolucionário. Teme ser comum. }\end{array}$ \\
\hline Mago & $\begin{array}{l}\text { É aquele que faz acontecer. Promove } \\
\text { "momentos mágicos" e transforma sonhos } \\
\text { em realidade. }\end{array}$ \\
\hline Inocente & $\begin{array}{l}\text { É otimista, sonhador. Acredita num mundo } \\
\text { melhor, que tudo pode ser perfeito: a casa, } \\
\text { o emprego, seu par, sua vida. Ele deseja } \\
\text { vivenciar o paraíso e tem como meta ser } \\
\text { feliz. } \\
\text { Desejo de pureza, bondade e simplicidade. }\end{array}$ \\
\hline Explorador & $\begin{array}{l}\text { Parte em busca de um mundo melhor. É } \\
\text { aventureiro, gosta de ir a lugares que } \\
\text { ninguém nunca foi. Seu desejo básico é ter } \\
\text { liberdade para explorar o mundo. }\end{array}$ \\
\hline Sábio & $\begin{array}{l}\text { É aquele que busca a verdade e o } \\
\text { conhecimento e os compartilha. Usa a } \\
\text { inteligência e análise para compreender o } \\
\text { mundo. }\end{array}$ \\
\hline
\end{tabular}

Fonte: livro "O herói e o fora da lei" de Margaret Mark e Carol Pearson (2012).

Nota: Dados trabalhados pelas autoras. 
O estudo apresentado no Quadro 01 servirá como apoio à análise de conteúdo e estrutural, pois concebe-se em método de inferência.

\section{TEMAS E FIGURAS: A ANCORAGEM} IDEOLÓGICA DA ENUNCIAÇÃO

Algirdas Julien Greimas, propõe que os discursos podem ser analisados estruturalmente, no que diz respeito ao enunciado propriamente dito, a semiótica de Linha Francesa oferece uma divisão da análise em diferentes graus de abstração, o que estabelece três níveis de análise que compõem o "Percurso Gerativo de Sentido", são eles: Nível Discursivo, Nível Narrativo e Nível Fundamental. A presente análise fará uma reflexão embasada em mecanismos inerentes ao Nível Discurso por ser este patamar o mais privilegiado, do percurso gerativo de sentido, por seu alto grau de concretude e que manifesta a ideologia do sujeito da enunciação.

Os mecanismos discursivos escolhidos são Figuras e Temas. Pelo procedimento da figurativização, figuras do conteúdo recobrem os percursos temáticos abstratos e atribui-Ihes traços de revestimento sensorial. Há etapas diferentes na figurativização: a figuração é a instalação das figuras , ou seja, o primeiro nível de especificação figurativa do tema, quando se passa do tema à figura; a iconização é o investimento figurativo exaustivo final, isto é, a última etapa da figurativização, com o objetivo de produzir ilusão referencial.

O tratamento figurativo dos temas propostos por determinados textos pode dizer muito sobre o universo ideológico no qual aquele texto se insere. Por conta disto, é imperativo que metodologia proposta pela semiótica apresente ferramentas teóricas que sejam operativas no tratamento de temas e figuras no nível discurso, como aponta Barros (1997).

Nessa medida, o conceito de Isotopia é de fundamental importância para a análise semiótica. Ele se refere à reiteração de elementos que ao se relacionarem sintagmaticamente em determinados contextos, compartilham um mesmo campo semântico. Em termos práticos, para determinar os temas e figuras apresentados no nível discursivo, o analista deve indicar um percurso sintagmático de elementos que apontam para uma determinada figura ou determinado tema, mesmo que este não esteja explícito. Greimas e Courtès (2008, p.278) afirmam que "do ponto de vista do enunciatário, a isotopia constitui um crivo de leitura que torna homogênea a superfície do texto, uma vez que ela permite elidir ambiguidades." 


\section{O CORPUS}

A Figura 01 apresenta uma decupagem fragmentada do comercial, representando as cenas mais expressivas para esta análise, por isto as cenas não estão numeradas sequencialmente. Na sequência, a trilha com a letra na íntegra, para facilitar o processo de análise estrutural e de conteúdo.

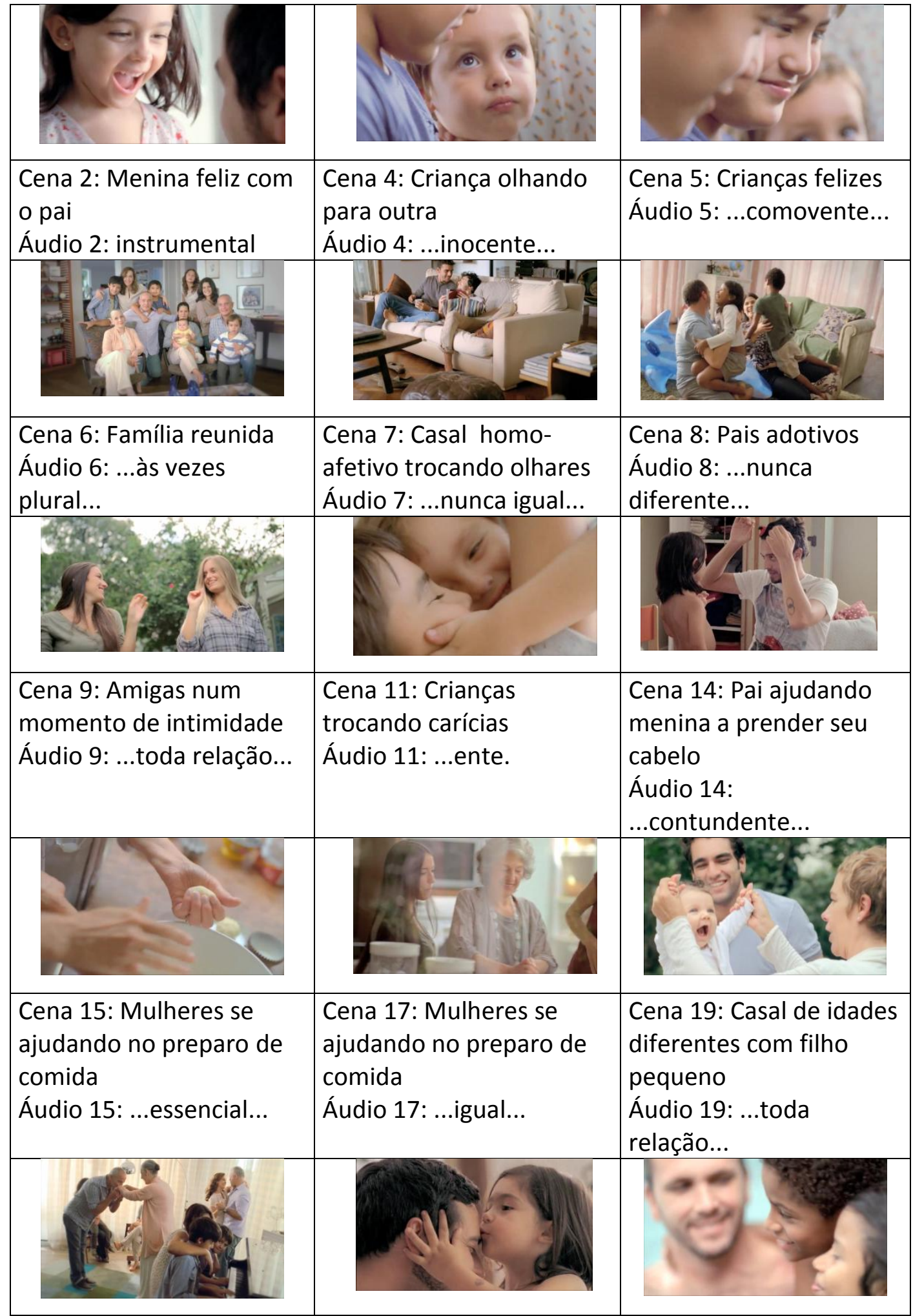




\begin{tabular}{|l|l|l|}
\hline $\begin{array}{l}\text { Cena 20: Cena familiar, } \\
\text { pessoas de várias idades } \\
\text { Áudio 20: ...é um } \\
\text { presente. }\end{array}$ & $\begin{array}{l}\text { Cena 23: Filha beijando o } \\
\text { pai } \\
\text { Áudio 23: ...nunca... }\end{array}$ & $\begin{array}{l}\text { Cena 25: Família multi- } \\
\text { étnica brincando na } \\
\text { piscina } \\
\text { Áudio 25: ...toda } \\
\text { relação... }\end{array}$ \\
\hline $\begin{array}{l}\text { Cena 28: Mãe e filha } \\
\text { Áudio 28: Quase nunca... }\end{array}$ & $\begin{array}{l}\text { Cena 35: Família } \\
\text { passeando no parque } \\
\text { Áudio 35: instrumental } \\
\text { Lettering: Toda relação... }\end{array}$ & $\begin{array}{l}\text { Cena 36: Mãe e filha se } \\
\text { abraçando } \\
\text { Áudio 36: instrumental } \\
\text { Lettering: Toda relação é } \\
\text { um presente. }\end{array}$ \\
\hline
\end{tabular}

Figura 01 . Decupagem com legenda do VT "Toda relação é um presente"

Fonte: www.youtube.com/watch?v=qddZVkW6FHY (2014)

Letra da trilha: "Toda relação é um presente"

"Às vezes incoerente, inocente, comovente.

Às vezes plural, nunca igual, nunca diferente.

Toda relação é um presente.

Às vezes irreverente, persistente, contundente.

Essencial, sempre igual, sempre diferente.

Toda relação é um presente.

Docemente inconstante, envolvente.

Nunca suficiente, toda relação... toda relação é um presente.

Quase nunca o bastante, transcendente, devagar, de repente.

Toda relação..."
IMPRESSÕES ANALÍTICAS SOBRE A MENSAGEM DO FILME PUBLICITÁRIO “TODA RELAÇÃO É UM PRESENTE"

A interpretação do filme permitiu identificar os sentidos explícitos e recuperar os sentidos implícitos vinculados ao discurso publicitário por meio da presença dos arquétipos dominante e subjacente da marca. Dessa forma foi possível questionar os valores que a marca e a publicidade em questão contribuem com a educação e com a sociedade.

É notável que a marca Natura desempenha um importante papel no imaginário que se constrói na práxis pois, como enunciadora, assume um discurso que redesenha os discursos sociais em circulação.

Atualmente vivemos inseridos e diante de uma sociedade tecnológica em que as relações humanas foram trocadas por relações tecnológicas. É muito comum hoje 
em dia as pessoas darem preferência ao contato por meio de mensagens instantâneas por celular ou e-mails. A conversa espontânea face a face tem sido substituída pelas mensagens escritas e já é visível grupos de pessoas não trocarem olhares e diálogos entre si quando podem estar juntas, em detrimento da possibilidade de fazer outros contatos tecnológicos.

De acordo com Citelli (2004, p. 12) "Estamos diante de processadores de textos e impulsos eletromagnéticos que capturaram a nossa alma dando em troca a possibilidade de convivermos nos paraísos virtuais."

A Natura trazendo como predominância o arquétipo “Inocente" recria e resgata por meio de seu discurso e filosofia, importantes valores sociais e comportamentais. Pode-se observar a presença deste arquétipo através dos signos do sorriso, na presença da criança, na natureza, no vestuário simples, nos gestos e no cenário casual. Ainda é possível identificar como arquétipo do "Inocente" a proximidade entre as pessoas e no tipo de contato estabelecido entre elas.

A marca exibe momentos simples na vida de pessoas comuns que trazem como consequência a felicidade. Resgata a importância das relações humanas, o contato entre elas e com a natureza, a simplicidade e a bondade.
A publicidade possui função pedagógica e pode ser entendida como um material formador, como saberes a serem assimilados, resultando, portanto, em aprendizagem que pode ocorrer em âmbito afetivo, atitudinal, opinativo ou de comportamento.

No âmbito afetivo a marca ressalta a importância da família, da brincadeira entre seus membros, da relação pais e filhos, da convivência e respeito entre gerações, além do auxílio mútuo.

A presença de relações homoafetivas, que no filme são simbolizadas pelo casal masculino e feminino, de alguma forma contribuem com questões de opinião e mostram que pode existir a liberdade do preconceito com a finalidade de bem estar e felicidade, pregando portanto a aceitação do outro.

Um arquétipo subjacente de forte presença no comercial é o Cara Comum. Ele pode ser observado na simplicidade das pessoas, na ausência de vaidade, do elitismo, do luxo ou glamour. As vestes são simples e nota-se a cumplicidade e a confiança entre as pessoas. O desejo básico desse arquétipo é de se conectar com os outros e pertencer a grupos.

Sob o aspecto atitudinal a marca apresenta algumas questões que ocorrem em nosso meio social com vistas a gerar reflexões nos leitores. Apresenta todos os 
tipos de relações como sendo verdadeiras e possíveis. As relações entre mãe e filha, pai e filha, entre casais homo-afetivos, entre casais com idades diferentes, casais de idosos e ainda a relação do ser humano com animais e até com a natureza. Dessa forma, tende-se a motivar o leitor ao abandono do preconceito e abertura a vários tipos de contatos e relacionamentos.

Quanto a aspectos comportamentais a propaganda por meio de seu discurso sugere a mudança em relação a algumas práticas de um cenário atual, ou seja, sugere possíveis reflexões quanto ao comportamento das pessoas, tendo como foco as relações marca ou produto e sim de uma ideia que prega a liberdade de preconceito e o estímulo às relações humanas.

Assim, a análise comprova que, sendo constituída de linguagem própria, fazendo uso de estratégias lexicais e visuais, a Publicidade influencia por meio de seus discursos, públicos específicos e definidos pela marca, no caso da Natura, ela incita por meio de elementos que configuram impacto positivo nas mensagens, contribuições importantes aos aspectos educativos, comportamentais, aos valores sociais e às estratégias de manipulação discursiva para o consumo.

\section{REFERÊNCIAS}

BACCEGA, M. A O impacto da publicidade no campo comunicação/educação. Cadernos de pesquisa ESPM/ Escola Superior de Propaganda e Marketing. Ano 1, n.3, set/out, São Paulo: ESPM, 2005. p. 11-94.

BARROS, Antônio e DUARTE, Jorge. Métodos e Técnicas de Pesquisa em Comunicação. Editora Atlas, 2006.

BARROS, D.L.P.de. Teoria Semiótica do texto. São Paulo: Editora Ática, 1997.

BRAGA, José Luiz; CALAZANS, Regina. Comunicação e Educação - Aprendizagens Mediáticas. 1 ed. São Paulo: Hacker Editores, 2001.

CITELLI, Adilson. Comunicação e Educação: a linguagem em movimento . 3ed. São Paulo: Editora Senac, 2004.

GREIMAS, A. J.; COURTÈS, J. Dicionário de Semiótica. São Paulo: Editora Contexto, 2008.

MARK, Margareth; PEARSON, Carol S. O herói e o fora da lei: como construir marcas extraordinárias usando 0 poder dos arquétipos. Editora Cultrix, 2012.

NATURA. Homepage institucional. Sobre a Natura. 2014. Disponível em: <www.natura.com.br> Acesso em: 03 abr. 2014.

Recebido para publicação em 26/05/2014 Revisado em 04/06/2014

Aceito em 28/06/2014 